Revista Destaques Acadêmicos, Lajeado, v. 12, n. 2, 2020. ISSN 2176-3070

DOI: http://dx.doi.org/10.22410/issn.2176-3070.v12i2a2020.2391

http://www.univates.br/revistas

\title{
ANÁLISE DA FORMAÇÃO CONTINUADA E PERMANENTE DOS PROFISSIONAIS DE ENFERMAGEM DE NÍVEL TÉCNICO DA ATENÇÃO BÁSICA DE UM MUNICÍPIO DO VALE DO TAQUARI/RS
}

\author{
Carina Guidoni ${ }^{1}$, Edson Moacir Ahlert ${ }^{2}$
}

\begin{abstract}
Resumo: A educação continuada proporciona o desenvolvimento de competências profissionais, ao longo da trajetória profissional, enquanto a educação permanente tem por objetivo desenvolver as competências de forma interdisciplinar, utilizando a prática como fonte do conhecimento e colocando o profissional para atuar ativamente no processo educativo. Este estudo analisa a formação continuada e permanente dos profissionais de enfermagem de nível técnico que atuam na atenção básica de um município do Vale do Taquari/RS e sugere a utilização de novas metodologias de ensino e aprendizagem no processo de educação permanente. Foi realizada uma pesquisa de caráter descritivo, com abordagem qualitativa; os dados foram obtidos por meio de questionário semiestruturado e após foram analisados conforme a técnica de análise de conteúdo proposta por Bardin, a qual envolve três etapas: pré-análise, exploração do material e tratamento dos resultados obtidos e inferência e interpretação. Como resultados do estudo surgiram três categorias analíticas: "Importância do processo de Educação Continuada, aporte para o exercício da profissão, facilidades e dificuldades de acesso", "Práticas de Educação Permanente desenvolvidas na instituição, metodologias utilizadas e participação dos profissionais" e "Avaliação e sugestões para qualificação do processo". Como resultados do estudo evidenciou-se que o processo de educação permanente realizado pela instituição possui algumas lacunas e sugeriu-se a introdução de metodologias ativas de ensino e aprendizagem para a qualificação do processo.
\end{abstract}

Palavras-chave: Técnico em Enfermagem. Educação continuada. Educação permanente.

\section{INTRODUÇÃO}

A Educação continuada impede a estagnação profissional e pessoal e envolve todos os processos de qualificação, que o profissional realiza durante

1 Bacharel em Enfermagem. Acadêmica do Curso de Pós-Graduação Lato Sensu - Especialização em Docência na Educação Profissional da Univates.

2 Professor da Univates. Mestre em Ambiente e Desenvolvimento. 
todo seu período de atuação. Enquanto a educação permanente busca aprimorar o processo de trabalho de acordo com as necessidades dos profissionais no dia a dia do local de trabalho, a educação continuada busca o desenvolvimento profissional e pessoal ao longo de toda trajetória profissional.

Segundo Balbino et al. (2010) há uma diferença clara entre educação permanente e educação continuada, ainda que ambas tenham a mesma ideia de continuidade ao processo de educação, elas estão assentadas sob princípios metodológicos diferentes, uma vez que a educação permanente procura ser objeto de transformação do processo de trabalho. Por outro lado Girade, Cruz e Stefanelli (2006) defendem que, independente do nome que essa prática receba, educação permanente, educação continuada ou educação em serviço, estas têm os mesmos propósitos que levam ao atendimento das metas da instituição, o desenvolvimento profissional e pessoal do indivíduo, a aquisição de conhecimentos, a mudança de atitude e ao pensamento que deve levar à reflexão.

A qualificação de Recursos Humanos na saúde ocorre através da efetivação de estratégias e ações com objetivo de desenvolver o potencial dos profissionais, no sentido de prepará-los para as mudanças e os desafios gerados no desempenho do trabalho diário nos diferentes espaços do SUS (MACHADO, 2003).

Em harmonia com esses objetivos, Silva, Pereira e Benko (1989), enfatizam que a educação continuada atuante pode conduzir à melhoria da assistência de enfermagem, promover satisfação no serviço e melhorar as condições de trabalho na busca de um objetivo comum, através da identificação de problemas, insatisfações, necessidades e a utilização de meios e métodos para saná-los.

A educação continuada permite ao profissional, o acompanhamento das mudanças que ocorrem na profissão, visando mantê-lo atualizado, aceitar essas mudanças e aplicá-las no seu trabalho. Considera-se então, a educação continuada como um conjunto de práticas educacionais que visam melhorar e atualizar a capacidade do indivíduo, favorecendo o seu desenvolvimento e sua participação eficaz na vida institucional (DILLY; JESUS, 1995).

No município onde se realizou o estudo, o processo de educação permanente é organizado pelos enfermeiros. Segundo Silva e Seiffert (2009) a maioria das instituições de saúde tem um setor que se preocupa com a educação permanente dos profissionais de saúde. A Organização Pan-Americana de Saúde (OPAS) recomenda que esse setor tenha como coordenador um enfermeiro. Essa participação é essencial, uma vez que é o enfermeiro que mantém contato direto com a equipe de enfermagem o que possibilita conhecer a sua realidade.

O presente artigo teve como objetivo verificar se a educação continuada dos técnicos de enfermagem que atuam na atenção básica de um município do 
Vale do Taquari/RS está ocorrendo e de que forma; além disso, objetivou-se avaliar a percepção desses profissionais sobre a educação permanente realizada no local e analisar a possibilidade da introdução de novas metodologias de ensino, capazes de melhorar o processo e permitir integrar a qualificação técnica e o aprimoramento do indivíduo de forma mais eficiente.

\section{EDUCAÇÃO PROFISSIONAL NA ÁREA DA SAÚDE}

Os cursos profissionalizantes na área da enfermagem iniciaram em 1934, em Belo Horizonte/MG, com a intenção de suprir a falta de assistência aos pacientes internados em hospitais. A formação de uma enfermeira era muito onerosa e demorada, então optou-se por cursos de auxiliar de enfermagem, que preparavam um grande número de pessoas para prestar assistência direta ao paciente, através de cursos de curta duração e com valor reduzido (CARVALHO, 1976).

Durante a década de 60 surge uma nova categoria profissional, o técnico de enfermagem. Também existia uma quarta categoria na enfermagem, a dos atendentes de enfermagem. Eles realizavam a parte mais simples do trabalho de enfermagem. $\mathrm{O}$ treinamento era realizado no próprio serviço e o funcionário necessitava de um nível de escolarização correspondente ao primário (ALMEIDA; ROCHA, 1986).

O perfil profissional de conclusão do técnico em enfermagem, delimitado pela Lei do Exercício Profissional, Lei Federal $\mathrm{n}^{\circ} 7.498 / 86$, e pelo Decreto $\mathrm{n}^{\circ}$ 94.466/87, refere que, sob supervisão do enfermeiro, aquele profissional deve exercer cuidados de promoção, prevenção, recuperação e reabilitação, obedecendo aos níveis de conhecimento e complexidade de ações que lhe são designados, referenciados nas necessidades de saúde individuais e coletivas e determinadas pelo processo saúde-doença (MINISTÉRIO DA SAÚDE, 1986).

\subsection{Educação Continuada}

A educação continuada é uma ferramenta essencial com a finalidade de melhorar o desempenho profissional que, se conduzida como um processo permanente possibilita o desenvolvimento de competência profissional, visando à aquisição de conhecimentos, de habilidades e de atitudes, para interagir e intervir na realidade além de auxiliar a minimizar os problemas advindos da defasagem na formação (SALUM; PRADO, 2014).

A educação continuada é um dos caminhos para uma assistência de qualidade, respeitando-se o paciente e o profissional, deve englobar programas de ensino que proporcionam aos trabalhadores oportunidades de aprendizagem e desenvolvimento de habilidades em suas ações profissionais, "integrando o processo produtivo ao educativo, contemplando as necessidades da instituição, mas também as necessidades, as expectativas de elaboração de conhecimentos, 
experiências que vão além das exigências profissionais imediatas, respeitando as particularidades pessoais" (SOUZA; CERIBELLI, 2004, p.768).

\subsection{Educação Permanente}

Segundo Ceccim (2005), a educação permanente pode ser entendida como educação em serviço quando reporta à formação como parte de um projeto de mudanças institucionais ou de orientação política das ações prestadas. $\mathrm{Ou}$, ainda, como educação continuada, quando relacionada à construção de quadros institucionais ou de carreiras. Ou até mesmo como educação formal de profissionais, quando voltada para projetos integrados, ensino e trabalho, com vistas à multiplicidade das vivências profissionais.

Segundo Ricaldoni e Sena (2006), educação permanente é um processo que ocorre dentro das instituições. $\mathrm{O}$ mesmo está relacionado ao processo de trabalho, e tem como objetivo ensinar através de situações do dia a dia. A educação permanente é uma prática institucionalizada que busca fortalecer as ações da equipe, centrada na resolução de problemas, promovendo a apropriação do saber científico.

De acordo com Paschoal, Mantovani e Méier (2007), a educação permanente é uma exigência na formação do indivíduo e requer um novo posicionamento frente ao conhecimento. Isso ocorre devido à necessidade de relacionar teoria e prática, não sendo possível separar ação do conhecimento. Neste contexto de crescimento e fortalecimento profissional, a prática baseada em evidências é uma ferramenta que torna ainda mais coesa e sistematizada a educação e a execução de tarefas.

Conforme Silva e Seiffert (2009), a educação permanente é um processo que promove o desenvolvimento do indivíduo e do setor onde ele trabalha. E uma oportunidade de aprendizado para os trabalhadores e usa o ambiente normal das atividades em saúde para que a aprendizagem seja mais significativa, ligada à prática.

A qualificação profissional tem como um de seus principais objetivos "a atualização e o aprimoramento em razão das constantes mudanças nos campos científico e tecnológico visando o atendimento das necessidades que os profissionais apresentam em seus processos de trabalho" (BRAGA; MELLEIRO, 2009, p. 1226). Os procedimentos de enfermagem sofrem constantes mudanças, desta forma, a atualização torna-se imprescindível para a correta realização das atividades diárias.

A Política Nacional de Educação Permanente em Saúde é uma proposta de ação estratégica que visa transformar e qualificar a atenção à saúde, os processos formativos, as práticas de saúde e pedagógicas, além de incentivar a organização das ações e dos serviços. A implantação dessa política leva a necessidade de um trabalho articulado entre o sistema de saúde e as 
instituições de ensino, destacando a formação e o desenvolvimento para o SUS, na perspectiva da educação permanente (CECCIM, 2005).

A consolidação do SUS tem exigido dos gestores de saúde, a identificação e a definição de estratégias para a resolução dos problemas de recursos humanos $(\mathrm{RH})$, apontando também a necessidade de fortalecimento das práticas de gestão nesse campo. O Desenvolvimento de $\mathrm{RH}$ representa atualmente um papel de suma importância para a consecução de um SUS democrático, equitativo e eficiente (GIL, 2005).

Se o propósito é apenas informar, esclarecer, tornar os profissionais mais sabedores do arcabouço técnico e teórico da profissão, as propostas de capacitações, treinamentos, reciclagens e similares podem dar conta dessa tarefa. Caso o propósito inclua a transformação da realidade visando à qualificação dos serviços prestados, a educação permanente se configura como uma opção capaz de colocar em análise o trabalho e as práticas cotidianas para atingir esse objetivo.

A informação é importante nesse processo, não somente como forma de se conhecer mais, e sim de se aproveitar o seu potencial de maneira crítica e consciente, transformando equipes de trabalho em "coletivos organizados de desenvolvimento de si e de seus entornos de trabalho e atuação na saúde" (CECCIM; FERLA, 2006).

Para Marquis e Huston (2010) as atividades de desenvolvimento de profissionais geralmente são realizadas por uma de três razões: estabelecer competências técnico-científicas, ético-políticas e sócio educativas contextualizadas que possibilitem atuar profissionalmente, compreendendo a natureza humana e suas dimensões; atingir as novas necessidades de aprendizagem; e atender a interesses dos funcionários em aprender coisas de áreas específicas.

Assim, deve-se realizar um levantamento de necessidades educacionais e somente após, iniciar o desenvolvimento dos programas no processo de trabalho, considerando as necessidades apresentadas pelos profissionais.

Entretanto, nos serviços de enfermagem, percebe-se a utilização de modelos e práticas tradicionais, que se deve, em muitos casos, à insegurança teórica dos profissionais, que ainda atuam na perspectiva do paradigma vigente, dificultando a contribuição para a implementação de modelos mais resolutivos na saúde (PASCHOAL; MANTOVANI; LACERDA, 2006).

Estratégias de ensino norteadas pelo método ativo têm como características principais: o aluno como centro do processo, a promoção da autonomia do aluno, a posição do professor como mediador, ativador e facilitador dos processos de ensino e de aprendizagem e o estímulo à problematização da realidade, à constante reflexão e ao trabalho em equipe (DIESEL; MARCHESAN; MARTINS, 2016). 
Bastos (2006) apresenta uma conceituação de Metodologias Ativas como "processos interativos de conhecimento, análise, estudos, pesquisas e decisões individuais ou coletivas, com a finalidade de encontrar soluções para um problema".

O enfermeiro, como principal responsável dentro da maioria das instituições de saúde, pela educação permanente, deve reavaliar de forma constante as metodologias utilizadas no processo de ensino e aprendizagem, buscando envolver os profissionais de forma ativa em seu processo de qualificação.

\section{PROCEDIMENTOS METODOLÓGICOS}

Este estudo trata-se de uma pesquisa com abordagem qualitativa. Podese considerar que a pesquisa qualitativa tem o objetivo de compreender a complexidade do contexto social e histórico em que estão inseridos os atores da investigação (GIL, 2017).

Para Gil (2017) a pesquisa qualitativa possibilita a utilização de múltiplos métodos para investigar um fenômeno. Ao oportunizar o contato entre os atores envolvidos, proporciona a análise de suas relações sociais, ou seja, a intervenção é fonte de estudo para o pesquisador e para os envolvidos. Esse tipo de pesquisa almeja a união entre teoria e prática, oportunizando a transformação da realidade.

Para este estudo, realizou-se aplicação de questionário do tipo semiestruturado, nas Unidades Básicas de Saúde de um município do Vale do Taquari/RS. O município dispõe de duas Unidades de Saúde, uma unidade onde funcionam duas estratégias de Saúde da Família e outra unidade básica localizada no centro do município.

Foi aplicado um questionário aos técnicos de enfermagem das unidades básicas de saúde do município, com 10 questões, dividido em três partes: - a primeira, relacionada ao perfil dos técnicos de enfermagem, como: gênero, idade, tempo de formação, tempo de exercício profissional e formação acadêmica; - a segunda, referente a dados funcionais, como período de trabalho, tempo de trabalho na instituição, experiências profissionais; - e a terceira, analisando aspectos considerados de maior relevância referente à Educação continuada e permanente, fatores relacionados ao processo, facilidades e dificuldades encontradas de acesso e espaço destinado a comentários que considerassem importantes, não contemplados nas perguntas.

A população do estudo foi composta pelos 5 técnicos de enfermagem que atuam nas unidades do município. Todos os técnicos de enfermagem foram abordados no seu local de trabalho, sendo informado o objetivo do estudo e solicitado sua participação voluntária e agendada data e local para aplicação do instrumento; todos os técnicos de enfermagem do município aceitaram participar do estudo. 
A coleta de dados foi realizada no mês de março de 2018, em dia e horários previamente agendados com os entrevistados, no próprio local de trabalho. No dia e horário agendado, após a assinatura do Termo de Consentimento Livre e Esclarecido, foi entregue o instrumento para ser respondido na presença da pesquisadora. Ao término, foi verificado se os instrumentos estavam completos e se procedeu a identificação.

A pesquisa foi desenvolvida de acordo com a Resolução $n^{\circ} 466$, de 12 de dezembro de 2012, que dispõe sobre a ética em pesquisas que envolvem seres humanos e aprovada pelo Comitê de Ética em Pesquisa da Univates, Parecer número 2.550.317, com anuência da Secretaria Municipal de Saúde do município, onde se desenvolveu o estudo.

Para a apreciação de dados, utilizou-se a técnica de análise de conteúdo, a qual envolve três etapas: pré-análise, exploração do material e tratamento dos resultados obtidos e inferência e interpretação (BARDIN, 2011).

Como forma de garantir o anonimato dos participantes, os resultados foram identificados e codificados pelas letras "TE", como forma de abreviar Técnico de Enfermagem e o respectivo número relativo à ordem das entrevistas.

\section{RESULTADOS E ANÁLISE DOS DADOS}

Os participantes do estudo são do sexo feminino, com idades que variam de 33 a 55 anos, o tempo de experiência profissional na área varia entre 7 e 30 anos, nenhum profissional atua em mais de uma instituição e todos possuem carga horária semanal de 37 horas.

Após coleta dos dados, utilizou-se a técnica de análise de conteúdo proposta por Bardin (2011), a qual, conforme já mencionado, envolve três etapas: pré-análise, exploração do material e tratamento dos resultados obtidos, inferência e interpretação. Depois da análise dos dados coletados, ocorreu a organização e definição dos temas, com as falas agrupadas em categorias temáticas. O terceiro momento correspondeu à agregação das categorias temáticas com respaldo do referencial teórico para análise e discussão. Surgiram então as seguintes categorias: "Importância do processo de educação continuada, aporte do mesmo para o exercício da profissão, facilidades e dificuldades de acesso", "Práticas de Educação Permanente desenvolvidas na instituição, metodologias utilizadas e participação dos profissionais" e "Avaliação e sugestões para qualificação do processo". As categorias, e nelas as respostas mais relevantes do questionário aplicado, são apresentadas a seguir.

\subsection{Importância do processo de Educação Continuada, aporte do mesmo para o exercício da profissão, facilidades e dificuldades de acesso}

A Educação Continuada é um processo dinâmico de ensino e aprendizagem, ativo e permanente, destinado a atualizar e melhorar a capacitação de pessoas, ou grupos, face à evolução científico tecnológica, às 
necessidades sociais e aos objetivos e metas institucionais. Assim, a educação continuada precisa ser considerada como parte de uma política global de qualificação dos trabalhadores de saúde, centrada nas necessidades de transformação da prática (MINISTÉRIO DA SAÚDE, 2004).

Sobre os fatores de motivação, para a busca da educação continuada, os técnicos de enfermagem citam a necessidade de qualificação e atualização. Verifica-se a necessidade de manterem-se atualizados, pois a área da saúde evolui de forma constante, e o acompanhamento dessas mudanças permite um melhor aporte para o exercício da profissão.

- TE1 - "A educação continuada é de extrema importância para a qualificação do profissional".

- TE2 - "Novos conhecimentos e atualizações para melhor desenvolver nosso trabalho e crescer em conhecimento. Pesquisando na internet, livros e meios de comunicação".

- TE4 - "O incentivo financeiro é sem dúvidas o mais atrativo. A internet proporciona muitas formas de conhecimento".

- TE4 - “Trabalhamos com promoção a saúde, quanto mais orientamos os pacientes melhor, mas para isso precisamos passar com sabedoria, e estarmos instruídos com competência".

Verificou-se que os profissionais estão conscientes da importância da atualização na profissão que exercem, e de como este processo pode agregar na qualidade da assistência prestada.

Os profissionais relataram quais as principais facilidades e dificuldades encontradas no processo de educação continuada, sendo que o surgimento de cursos a distância foi citado como um dos facilitadores do processo.

- T1 - "As facilidades encontradas atualmente são os cursos online, pois podemos fazer a distância e em horário que teria disponibilidade, porém os mesmos ainda são bastante caros para nossa baixa remuneração".

- T2 - "Dificuldade financeira, pois tenho custo para me deslocar ao trabalho e não recebemos vale-transporte"

- T5 - "As dificuldades são financeiras e a disponibilidade de cursos na região. As facilidades são os cursos EAD".

Uma das estratégias para o desenvolvimento da Educação Continuada é a educação à distância (EAD), que vem se mostrando como uma estratégia eficaz para a educação, principalmente, para adultos inseridos no mercado de trabalho. Tem crescido o número de cursos nessa modalidade, difundidos no mundo inteiro utilizando a internet ou sistemas de rede similares como métodos de ensino e aprendizagem (ORTIZ; RIBEIRO; GARANHANI, 2008).

Como citado por alguns profissionais, a educação a distância é uma estratégia bastante eficaz para o processo de educação continuada, pois as 
facilidades para o acesso da mesma proporcionam a um número cada vez maior de profissionais, a oportunidade de aprendizagem, sem a necessidade de deslocamento para aulas presenciais em centros de ensino, o que impedia muitos profissionais de qualificarem-se.

\subsection{Práticas de Educação Permanente desenvolvidas na instituição, metodologias utilizadas e participação dos profissionais}

Para efetivar a Educação Permanente em Saúde, é necessário buscar o conhecimento a partir das necessidades do cotidiano de trabalho dos profissionais, do mesmo modo que a educação em saúde, sendo construída por meio da problematização da realidade local. A educação em saúde deve ter papel potencializador para romper e contribuir na subjetividade dos sujeitos, o compartilhamento de saberes, a autonomia, o diálogo, as relações mais igualitárias, e a criticidade, devem estar entremeadas nesse processo ( RENOVATO; BAGNATO, 2012).

Estudos apontam que a noção da Educação Permanente ainda se encontra voltada ao modelo de educação continuada, com forte tendência à educação bancária, o que está em contradição com o preconizado pela Política Nacional de Educação Permanente em Saúde. Reforça-se que para se ter uma aprendizagem significativa, e consequentemente uma atenção integral, é essencial a problematização das práticas de assistência, ensino, gestão e participação popular, bem como a articulação entre esses segmentos (SILVA; FURTADO, 2015).

Quando questionados a respeito dos tipos às práticas (palestras, oficinas e outras dinâmicas), realizadas na instituição, 100\% dos participantes do estudo colocaram que o único método utilizado neste processo é o expositivo, por meio de palestras.

- T1 - "Somente palestra".

- T2 - "Palestra".

- T3 - "Somente por exposição".

- T4 - "Somente palestra".

- T5 - "Palestras".

Os profissionais colocaram que participam de todas as atividades promovidas pela instituição. Porém, alguns referem que as mesmas são monótonas e até mesmo desinteressantes. Verifica-se, neste sentido, a necessidade de reavaliar as metodologias utilizadas, introduzindo novas metodologias, de forma a qualificar o processo.

- T1 - "Participo, porém acho que são muito monótonas e todo ano repetimos os mesmos temas, mas contribui".

- T2 - "São realizadas só palestra e sempre os mesmos temas". 
- T3 - "Quando surge algo sempre participo. Porém quase não há nada de interessante".

- T4 - "Somente palestra, acho que existem inúmeras formas de capacitação, acredito que estudos de casos seriam muito mais interessantes".

- T5 - "São realizadas sempre da mesma forma, com a realização de uma palestra, dada por uma das enfermeiras".

Foi possível verificar que os profissionais participam das atividades realizadas, porém não consideram as mesmas atraentes. Salienta-se que a atualização na área da saúde deve ser permanente e constante, para que os profissionais possam manter-se a par das mudanças que ocorrem quase que diariamente. Desta forma, as instituições devem buscar qualificar este processo, fazendo com que os profissionais não participem dos mesmos, somente por ser uma exigência das instituições, mas por considerarem estes momentos importantes para sua formação profissional e pessoal.

\subsection{Avaliação e sugestões para qualificação do processo}

As instituições de saúde precisam implementar projetos de educação permanente, oportunamente articulados com instituições formadoras de recursos humanos. Tais projetos não precisam produzir eventos na instituição, podem acontecer em qualquer lugar, em qualquer horário, com desenvolvimento das competências, foco nas mudanças para melhorias e com a participação de todos os atores envolvidos, inclusive gestores (SARRETA, 2009).

Às demandas para a capacitação não se definem somente a partir de uma lista de necessidades individuais de atualização, nem das orientações dos níveis centrais, mas prioritariamente, desde a origem dos problemas que acontecem no dia a dia, da organização do trabalho em saúde. Desse modo, transformar a formação e a gestão do trabalho em saúde não pode ser considerado uma questão simplesmente técnica, pois envolve mudanças nas relações, nos processos, nos atos de saúde e, principalmente, nas pessoas (JAEGER; CECCIM, 2004).

Verificou-se através de um dos relatos, que os profissionais não participam do processo de elaboração do cronograma de temas a serem trabalhados, nem mesmo são consultados a respeito do assunto. Os profissionais sugeriram diversos temas para serem trabalhados, sendo citados temas referentes a atendimento de urgência e emergência, ferimentos, entre outros. Acredita-se que o levantamento de temas considerados importantes pelos profissionais deve ser realizado levando em conta as demandas que surgem no dia a dia das Unidades de Saúde 
- T2 - "Não somos consultados sobre os temas, os mesmos seguem o mesmo cronograma todos os anos. Gostaria de receber atualizações em feridas, pois sempre surgem coisas novas, etc".

- T3 - "Parada cardiorrespiratória, resgate, ética".

- T4 - "Atendimento de urgência e emergência, ética profissional".

Ao serem questionados sobre de que forma desejavam que fosse realizado o processo de educação permanente na instituição onde atuam e de quais metodologias preferem, sendo dados exemplos como: aula expositiva, aula dialogada, palestra, leitura e discussão de textos, debates, estudo de problemas e ou casos, muitos colocaram que todas as formas seriam válidas. Verificou-se então que a inserção de metodologias ativas seria bem aceita, tratando-se de uma alternativa para tornar o processo mais atraente.

As metodologias ativas vão ao encontro dessa proposta, pois os educandos assumem, desde o início, o papel de sujeitos ativos e os educadores de estimuladores e facilitadores da aprendizagem, numa relação afetiva de troca e crescimento mútuo. Fundamenta-se no diálogo entre o educando e o educador e na construção coletiva do conhecimento (DUARTE, 2011).

- T1 - "Acho que todas alternativas seriam boas, desde que mudassem a forma e acrescentarem novos conteúdos".

- T2 - "Todas as formas seriam importantes, acho que oficina, relato de experiência, além de algo que pudéssemos praticar... seria muito bom".

- T5 - "Acredito que devíamos trabalhar com estudos de caso, debates... enfim variar as formas de capacitação".

Assim, algumas possibilidades, como a introdução de um cronograma de capacitações, com temas também baseados nas necessidades apontadas pelos profissionais da instituição poderão contribuir de forma bastante significativa para a qualificação do processo, pois ao terem suas demandas atendidas, acredita-se que os mesmos passarão a valorizar mais estes momentos, além da organização de momentos para esclarecimentos de dúvidas que surgem no dia a dia da instituição.

Outro fator que se sugere que possa ser revisto refere-se às metodologias de ensino adotadas pela instituição em suas capacitações. Ficou evidente, durante a entrevista e confirmadas após a análise dos dados, que a introdução de novas estratégias, mais ativas e dinâmicas, que geram maior envolvimento com o conteúdo e maior participação técnicos de enfermagem no processo de aprendizagem, poderá contribuir de forma significativa para aprimorar o processo.

Para Berbel (2011), as metodologias ativas baseiam-se em formas de desenvolver o processo de aprender, utilizando experiências reais ou 
simuladas, visando às condições de solucionar, com sucesso, desafios advindos das atividades essenciais da prática social, em diferentes contextos.

A introdução de metodologias ativas como estudos de casos, júri simulado e problematização entre outros, pode proporcionar o desenvolvimento da autonomia profissional e o envolvimento dos profissionais de forma ativa no seu processo de qualificação.

\section{CONSIDERAÇÕES FINAIS}

O estudo permitiu verificar como é desenvolvido o processo de educação continuada e a importância que os mesmos atribuem ao processo e analisar e sugerir modificações no processo de educação permanente disponibilizado aos técnicos de enfermagem das Unidades Básicas de Saúde de um município do Vale do Taquari/RS. Verificou-se que esse último apresenta algumas lacunas, destacando-se principalmente a metodologia expositiva de ensino utilizada e a elaboração do cronograma de temas a serem abordados, sem a participação dos profissionais técnicos neste processo, o que os impossibilita de sugerirem assuntos que consideram relevantes para sua qualificação.

Desta forma, sugere-se que seja feita uma reavaliação do processo de educação permanente utilizado pela instituição, passando-se a observar, durante a elaboração do cronograma, os temas a serem abordados, as demandas apresentadas pelos profissionais, atendendo assim às necessidades dos mesmos, fazendo, desta forma, com que o processo se torne mais atrativo e participativo.

Outro fator a ser repensado refere-se às metodologias de ensino adotadas no processo, com a introdução de novas e diferentes abordagens, que tornem o processo mais dinâmico, fazendo com que o profissional atue de forma direta na construção de novos saberes, permitindo assim, que a qualificação ocorra de maneira mais eficiente.

\section{REFERÊNCIAS}

ALMEIDA, M. C. P.; ROCHA, J. S. Y. O saber de enfermagem e sua dimensão

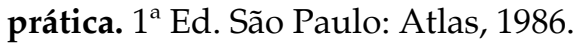

BALBINO, Aldiania Carlos; BEZERRA, Mirna Marques; FREITAS, Cibelly Aliny Siqueira Lima; ALBUQUERQUE, Izabelle Mont' Alverne Napoleão; DIAS, Maria Socorro de Araújo; PINTO, Vicente de Paulo Teixeira. Educação permanente com os auxiliares de enfermagem da estratégia saúde da família. Trab. Educ. Saúde, Rio de Janeiro, v.8 n.2, p. 249-266, jul./out.2010. Disponível em: http:/ /www.revista.epsjv. fiocruz.br//include/mostrarpdf.cfm?Num=296. Acesso em: 08 de mar. 2018

BRAGA, A. T.; MELLEIRO, M. M. Percepção da equipe de enfermagem acerca de um serviço de educação continuada de um hospital universitário. Rev. Esc. Enferm. 
USP, v.43, p. 1216, 2009. E-book. Disponível em: <http:/ / www.scielo.br/pdf/reeusp/ v43nspe2/a12v43s2.pdf>. Acesso em: 05 mar. 2018.

BERBEL, N. A. N. As metodologias ativas e a promoção da autonomia de estudantes. Ciências Sociais e Humanas. Londrina, v. 32, n. 1, p. 25-40, jan./jun. 2011.

BARDIN, L. Análise de Conteúdo. São Paulo: Edições 70; 2011.

BASTOS, C. C. Metodologias ativas. 2006. Disponível em: <http:/ /

educacaoemedicina.blogspot.com.br/2006/02/metodologias-ativas.html>. Acesso em: 12 fev. 2018.

CARVALHO, A. C. Associação Brasileira de Enfermagem - 1926-1976. Documentário. Brasília, ABEn, 1976, 514p.

CECCIM, R. B. Educação Permanente em Saúde: desafio ambicioso e necessário. Interface - Comunicação Saúde, Educação, v.9, n.16, p.161-77, set.2004/fev.2005. Dísponivel:<http://www.escoladesaude.pr.gov.br/arquivos/File/text os\%20eps/ educacaopermanente.pdf $>$. Acesso em: 17 jan. 2018.

CECCIM, R. B; FERLA, A. A. Educação Permanente em Saúde. In: Escola Politécnica de Saúde Joaquim Venâncio, organizadora. Dicionário da Educação Profissional em Saúde. Rio de Janeiro: EPSJV; 2006, p. 107-12.

DILLY, C. M. L.; JESUS, M. C. P. Processo educativo em enfermagem: das concepções pedagógicas à prática profissional. São Paulo: Robe, 1995. Cap. 2, p. 51-122: Situações de ensino em enfermagem.

DIESEL, Aline; MARCHESAN, Michele Roos; MARTINS, Silvana Neumann. Metodologias Ativas de Ensino na Sala De Aula: Um Olhar de Docentes da Educação Profissional Técnica de Nível Médio. 2016. Disponível em:<http:/ /www. univates.br/revistas/index.php/signos/article/view/1008>. Acesso em 10.mar. 2018.

DUARTE, L. R. Ensino em serviço para o desenvolvimento de práticas educativas no SUS pelos agentes comunitários de saúde. In: Mialhe FL, organizador. O agente comunitário de saúde: práticas educativas. Campinas: Editora da UNICAMP; 2011.

GIL, Antonio Carlos. Como elaborar projetos de pesquisa. Rio de Janeiro: Atlas, 2017.

GIL, C. R. R. Formação de recursos humanos em saúde da família: paradoxos e perspectivas. Cadernos de Saúde Pública, Rio de Janeiro, v. 21, n. 2, p. 490-498, 2005.

GIRADE, Maria da Graça; CRUZ, Emirene Maria Navarro Trevizan da; STEFANELLI, Maguida Costa. Educação continuada em enfermagem psiquiátrica: reflexão sobre conceitos. Rev. esc. enferm. USP, São Paulo, v. 40, n. 1, p.105-10 Mar. 2006. Disponível em: <http:/ / www.scielo.br/scielo.php?script=sci_arttext\&pid=S008062342006000100015\&lng=en\&nrm=iso >. Acesso em: 02 mar. 2018 
JAEGER, M. L.; CECCIM, R. B. Política de Educação e Desenvolvimento para o SUS: caminhos para a Educação Permanente em Saúde. Brasília: Ministério da Saúde, 2004.

MACHADO, M. H. Mercado de trabalho em saúde. In: FALCÃO, A. et al. (Orgs.). Observatório de recursos humanos em saúde no Brasil: estudos e análises. Rio de Janeiro: Editora FIOCRUZ, 2003.

MARQUIS, B. L., HUSTON, C. J. Administração e liderança em enfermagem: teoria e prática. Tradução de Regina Garcez. 6 ed. Porto Alegre: Artmed, 2010.

Ministério da Saúde. Decreto n ${ }^{\circ}$ 94.406/87, de 08 de junho de 1987: regulamenta a Lei $\mathrm{n}^{\mathrm{o}} 7.498$, de 25 de junho de 1986, que dispõe sobre o exercício da enfermagem, e dá outras providências. Brasília, 1987. Disponível em: <http:/ / www.planalto.gov.br/ ccivil_03/decreto/1980-1989/d94406.htm>. Acesso em: 10 mar. 2018.

Ministério da Saúde. Portaria 196 que trata de pesquisa com seres vivos. Brasília; Ministério da Saúde; 1996. E-book. Disponível em: <http://bvsms.saude.gov.br/bvs / saudelegis/cns/1996/res0196_10_10_1996.html>. Acesso em: 25 fev. 2018.

Ministério da Saúde. Política de educação e desenvolvimento para o SUS: caminhos para a educação permanente em saúde - pólos de educação permanente em saúde. Brasília (DF): MS, 2004. Disponível em: <http:/ /bvsms.saude.gov.br/bvs/ publicacoes/politica2_vpdf.pdf>. Acesso em: 05 fev. 2018.

ORTIZ, M. C. L; RIBEIRO, R. P; GARANHANI, M. L. Educação à distância: uma ferramenta para educação permanente de enfermeiros que trabalham com assistência perioperatória. Cogitare Enferm 2008 Out/Dez; 13(4):558-65. Disponível em: <www. researchgate.net/publication/274172143>. Acesso em: 19 jan. 2018.

PASCHOAL, A. S; MANTOVANI, M. F; LACERDA, M. R. A educação permanente em enfermagem: subsídios para a prática profissional. Revista Gaúcha Enfermagem, Porto Alegre, v. 27, n. 3, p. 336-343, set. 2006. Disponível em: <http:seer.ufrgs.br/ RevistaGauchadeEnfermagem/article/view/4621>. Acesso em: 19 jan. 2018.

\section{PASCHOAL, A. S; MANTOVANI, M. F; MÉIER, M. J. Percepção da educação} permanente, continuada e em serviço para enfermeiros de um hospital de ensino. Scielo Rev. Es. Enferm. USP; Vol.41 n³. São Paulo Set. 2007. Disponível em: <http:/ / www.scielo.br/pdf/reeusp/v41n3/19.pdf>. Acesso em: 17 jan. 2018.

RENOVATO, R. D.; BAGNATO, M. H. S. Da educação sanitária para a educação em saúde (1980-1992): discursos e práticas. Rev. Eletr. Enf. [Internet]. 2012 jan/ mar;14(1):77-85. Disponível em: <http://www.fen.ufg.br/fen_revista/v14/n1/pdf/ v14n1a09.pdf $>$. Acesso em: 05 fev. 2018.

RICALDONI, C. A. C.; SENA, R. R. Educação permanente: uma ferramenta para pensar e agir no trabalho de enfermagem. Rev. LatinoAm. Enfermagem, Ribeirão Preto, v. 14, n. 6, p. 14-20, dez. 2006. Disponível em: <http:/ / www.scielo.br/pdf/ rlae/v14n6/pt_v14n6a02.pdf>. Acesso em: 19 jan. 2018. 
SARRETA, F. O. Perspectivas da educação permanente em saúde. Educação permanente em saúde para os trabalhadores do SUS. São Paulo: Editora UNESP; São Paulo: Cultura Acadêmica; 2009.

SILVA, G. M.; SEIFFERT, O. M. L. B. Educação continuada em enfermagem: uma proposta metodológica. Rev. Bras. Enfermagem, Brasília, v. 62, n. 3, p. 362-366, junho 2009. Disponível em: <http://www.scielo.br/pdf/reben/v62n3/05.pdf>. Acesso em: 19 jan. 2018.

SILVA, M. J. P.; PEREIRA L. L.; BENKO, M. A. Educação continuada: estratégia para o desenvolvimento do pessoal de enfermagem. Rio de Janeiro: Marque-Saraiva. 1989.

SILVA, L. S.; FURTADO, L. A. R. Educação permanente em saúde e Estratégia Saúde da Família: revisão integrativa. Rev UNIABEU. 2015 - mai-ago;8(19):305-20. Disponível em: <http://revista.uniabeu.edu.br/index.php/RU/article/view/1764>. Acesso em: 19 jan. 2018.

SALUM, N. C., PRADO, M. L. A educação permanente no desenvolvimento de competências dos profissionais de enfermagem. Texto Contexto Enferm, Florianópolis, v. 23, n.2, p. 301-8, abr-jun, 2014. Disponível em:<http:/ / www.scielo. br/pdf/tce/v23n2/pt_0104- 0707-tce-23-02-00301.pdf>. Acesso em: 20 jan. 2018.

SOUZA, M. C. B.; CERIBELLI, M. I. P. F. Enfermagem no centro de material esterilizado: a prática da educação continuada. Rev. Latino-Am. Enfermagem [online]., v.12, n.5, p. 767- 774, 2004. Disponível em: <http:/ / www.scielo.br/pdf/ rlae/v12n5/v12n5a10.pdf > Acesso em: 20 jan. 2018. 